\title{
Ethanol and acetic-acid tolerance in Indian geographical populations of Drosophila immigrans
}

\author{
R Parkash*, Neena, Shamina \\ Department of Biosciences, Maharshi Dayanand University, Rohtak, 124001, India
}

(Received 10 September 1993; accepted 25 March 1994)

\begin{abstract}
Summary - Indian geographical populations of Drosophila immigrans revealed a lack of allozymic variation at the alcohol dehydrogenase locus. Latitudinal clines of ethanol tolerance (1.5-4.2\%) and acetic-acid tolerance (2.9-4.9\%) were observed in adult individuals of 4 geographical populations of Drosophila immigrans. Thus, both ethanol and acetic-acid tolerance decreased towards the equator. The parallel patterns of utilisation of ethanol and acetic acid seem to be correlated with the concentrations of these 2 metabolites in natural food resources. Thus, intra-specific differences for ethanol and acetic-acid tolerance could be adaptively maintained by spatially varying fermenting habitats along the north-south axis of the Indian sub-continent.

ethanol tolerance / acetic-acid tolerance / clinal variation / geographical population / Drosophila immigrans
\end{abstract}

Résumé - Tolérance à l'éthanol et à l'acide acétique de populations géographiques de Drosophila immigrans. Des populations géographiques de Drosophila immigrans ont révélé une absence de variation allozymique au locus de la déshydrogénase alcoolique. Des clines latitudinaux de tolérance à l'éthanol (de 1,5 à 4,2\%) et à l'acide acétique (de 2,9 à 4,9\%) ont été observés chez les adultes de 4 populations géographiques de $\mathrm{D}$ immigrans. La tolérance à l'éthanol et à l'acide acétique décrô̂t quand on se rapproche de l'équateur. Les modes d'utilisation de l'éthanol et de l'acide acétique sont parallèles et semblent liés aux concentrations de ces 2 métabolites dans les ressources alimentaires naturelles. Ainsi les différences intraspécifiques de tolérance à ces substances pourraient-elles être maintenues sous l'effet de la sélection naturelle dans des conditions de fermentation soumises à des variations spatiales le long d'un axe nord-sud du sous-continent indien.

tolérance à l'éthanol et à l'acide acétique / variation clinale / populations géographiques / Drosophila immigrans

* Correspondence and reprints: 446/23 (Near Park), DLF Colony, Rohtak, 124001, Haryana, India. 


\section{INTRODUCTION}

Colonising species populations offer most suitable material for micro-evolutionary studies (Endler, 1977, 1986). Eight Drosophila species have been known as cosmopolitan while 21 drosophilids have been designated as wide-spread (David and Tsacas, 1981; Lemeunier et al, 1986). Many species of the drosophilidae family feed on diverse types of fermenting and rotting fruits, vegetables, cacti, flowers and decaying organic food materials (Carson, 1971; Atkinson and Shorrocks, 1977). Ethanol is the end product of fermentation, and ethanol vapours provide a normal energy source in $D$ melanogaster (Parson, 1983). Ethanol is converted into acetic acid via acetaldehyde and thus concentrations of these 2 metabolites are generally found in natural habitats of the Drosophila species. Recently acetic acid has been found to be a resource parallel to that of ethanol (Chakir et al, 1993).

The phenomenon of ethanol tolerance has been studied from the ecological, physiological and genetic view points in $D$ melanogaster (McKenzie and Parsons, 1972; Parsons, 1983). Alcohol dehydrogenase (ADH) is known to be involved in the utilisation and detoxification of exogenous alcohols. The fermentation byproducts produced in the environment depend on the type of microflora (yeasts and other microbes) involved and the types of organic matter undergoing decomposition (Parsons, 1983). Thus, it can be predicted that diverse types of drosophilids could reflect interspecific differences in tolerance to different alcoholic resources. David and Van Herrewege (1983) revealed $D$ melanogaster and $D$ lebanonsis as highly ethanol tolerant while many species were found to be ethanol sensitive. Except for a single preliminary study on a $D$ immigrans population from Australia (Parsons and Spence, 1981), information on $D$ immigrans populations from temperate and sub-tropical parts of the world is still lacking.

$D$ melanogaster populations living in wine cellars (ethanol rich) and in the surroundings (with low ethanol concentration) have revealed microdifferentiation in the alcohol tolerance as well as in $A d h^{\mathrm{F}}$ frequency (Alonso-Moraga et al, 1988). However, such information on microspatial differentiation in other drosophilids is lacking. $D$ immigrans populations were found to exploit man-made alcoholic fermentation in sugar mills in India, and therefore it was considered worthwhile to analyse the possibility of microspatial differentiation in ethanol tolerance in $D$ immigrans populations from sugar-mills versus fruit stalls. The objectives of the present study were to analyse acetic-acid and ethanol utilisation in 4 geographical populations of $D$ immigrans as well as to analyse microspatial differentiation in ethanol and acetic-acid utilisation in local sugar-mill versus fruit-stall populations of this species.

\section{MATERIALS AND METHODS}

Mass bred populations of $D$ immigrans from north India (Manali, $32^{\circ} 0^{\prime} \mathrm{N}$ and Rohtak, $28^{\circ} 54^{\prime} \mathrm{N}$ ) and south India (Pune, $18^{\circ} 35^{\prime} \mathrm{N}$ and Bangalore, $12^{\circ} 58^{\prime} \mathrm{N}$ ) were used for ethanol and acetic-acid utilisation as well as ADH polymorphism. Homogenates of single individuals were subjected to electrophoresis at $250 \mathrm{~V}$ and $25 \mathrm{~mA}$ at $4^{\circ} \mathrm{C}$ for $4 \mathrm{~h}$. The gel slices were stained for the ADH gene-enzyme system by standard staining procedures (Harris and Hopkinson, 1976). The adult 
ethanol and acetic-acid tolerance patterns were assessed following the procedures of Starmer et al (1977). Groups of 10 males or 10 females, grown on a killed yeast medium (without any ethanol), were aged for $3 \mathrm{~d}$ on fresh Drosophila food medium and then transferred with the help of an aspirator to air-tight plastic vials. The flies were not etherised for all the experiments. The control vials contained $2 \mathrm{ml}$ of $2 \%$ sucrose solution absorbed on cellulose wool in order to prevent starvation, while treatment vials were supplemented with various concentrations of ethanol or acetic acid. Four replicates were performed for all the experiments. For each concentration, 40 males and 40 females were treated with a range of 6-8 different concentrations of ethanol or acetic acid. The male and female individuals did not reveal any significant difference in ethanol or acetic-acid tolerance and thus the data for the 2 sexes were averaged for all experiments. The effects of metabolic alcoholic vapours were assessed from the number of flies alive after various time intervals and $\mathrm{LT}_{50}$ values were expressed as the number of hours at which $50 \%$ of the flies died and were estimated by linear interpolation. The ethanol and aceticacid threshold values were used as indices, $i e$ if the vapours were utilised as resources then $\mathrm{LT}_{50}$ maximum/ $\mathrm{LT}_{50}$ control was found to be more than 1 ; if this ratio was less than 1, then it acted as stress, and the threshold values were determined when $\mathrm{LT}_{50}$ maximum $/ \mathrm{LT}_{50}$ control $=1$.

\section{RESULTS}

The ADH electrophoretic phenotypes revealed 2 banded patterns of faster mobility. Fifty to 60 individuals of each population did not reveal any variation in the number as well as mobility value of $\mathrm{ADH}$ phenotypes. These 2 banded patterns were found to be quite close in mobility to that of $D$ melanogaster individuals homozygous for the fast electromorph $\left(A d h^{\mathrm{F}}\right)$. Thus, $D$ immigrans populations possess the fast electromorph $\left(A d h^{\mathrm{F}}\right)$. The $A d h$ locus was found to be monomorphic in all the populations of $D$ immigrans. The northern and southern populations of $D i m m i$ grans revealed no genetic divergence at the $A d h$ locus. The longevity data revealed that south Indian populations of Bangalore had a longevity of $74 \mathrm{~h}$ compared with $162 \mathrm{~h}$ for the north Indian populations of Manali (table I). The data on $\mathrm{LT}_{50}$ maximum/LT $\mathrm{L}_{50}$ control (which constitute a measure of resource versus stress) for the $4 \mathrm{D}$ immigrans populations are shown in figure 1 . The adult ethanol threshold values were found to vary clinally in the range of 1.3 to $3.9 \%$ among 4 populations of $D$ immigrans from south to north localities of the Indian sub-continent (table I). Thus, ethanol concentration in the range of 3.3 to $3.9 \%$ served as a resources for north Indian populations while significantly lower ethanol concentrations (1.3-1.7\%) could be utilised by south Indian populations of $D$ immigrans.

Since all 4 Indian populations of $D$ immigrans could utilise both ethanol and acetic acid as a resource up to $3 \%$, comparative longevity effects at $3 \%$ revealed parallel interpopulational divergence, ie under experimental conditions, longevity for northern populations was found to be $10 \mathrm{~d}$ as compared with $5 \mathrm{~d}$ in southern populations. $\mathrm{LC}_{50}$ ethanol concentrations were calculated from mortality data of adults on the 3 rd day of ethanol treatment and these $\mathrm{LC}_{50}$ values revealed clinal variation in the range of 1.5 to $4.2 \%$, ie southern populations of $D$ immigrans showed significantly lower ethanol tolerance than the north Indian 


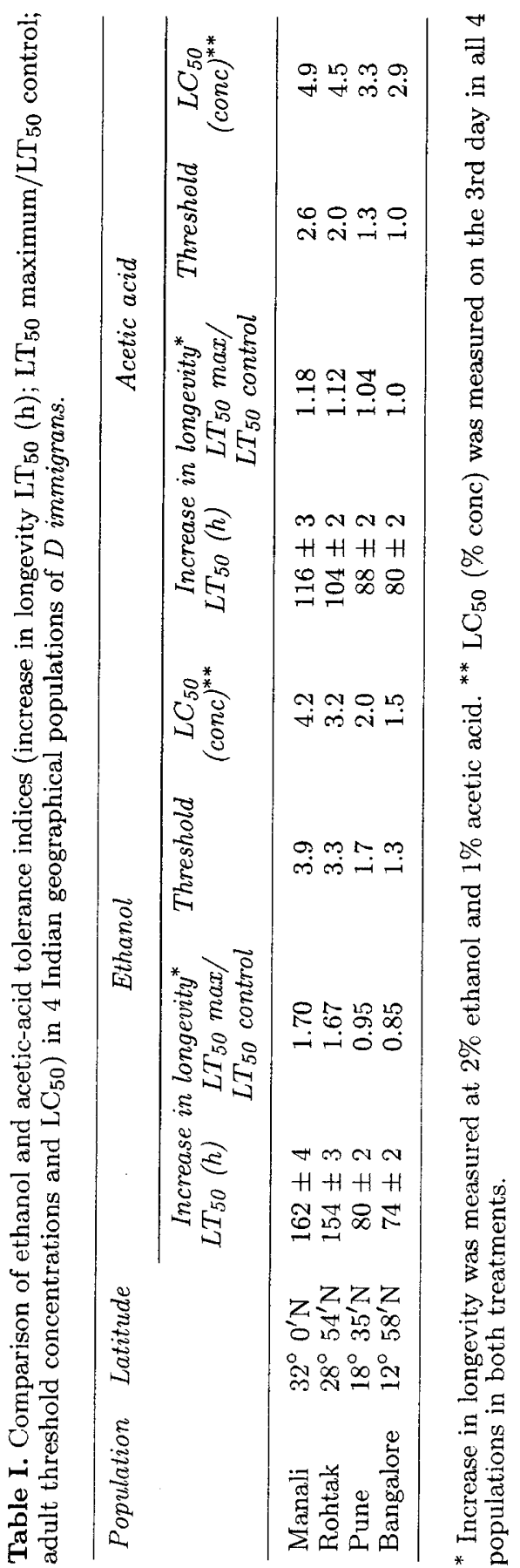


populations (figure $2 \mathrm{a}$ ). Thus, the maximum mortality was observed at $2 \%$ ethanol in south Indian populations compared with $4.2 \%$ in north Indian populations of $D$ immigrans. The correlation was found to be significantly higher between latitude and adult ethanol tolerance $(r=0.99)$.

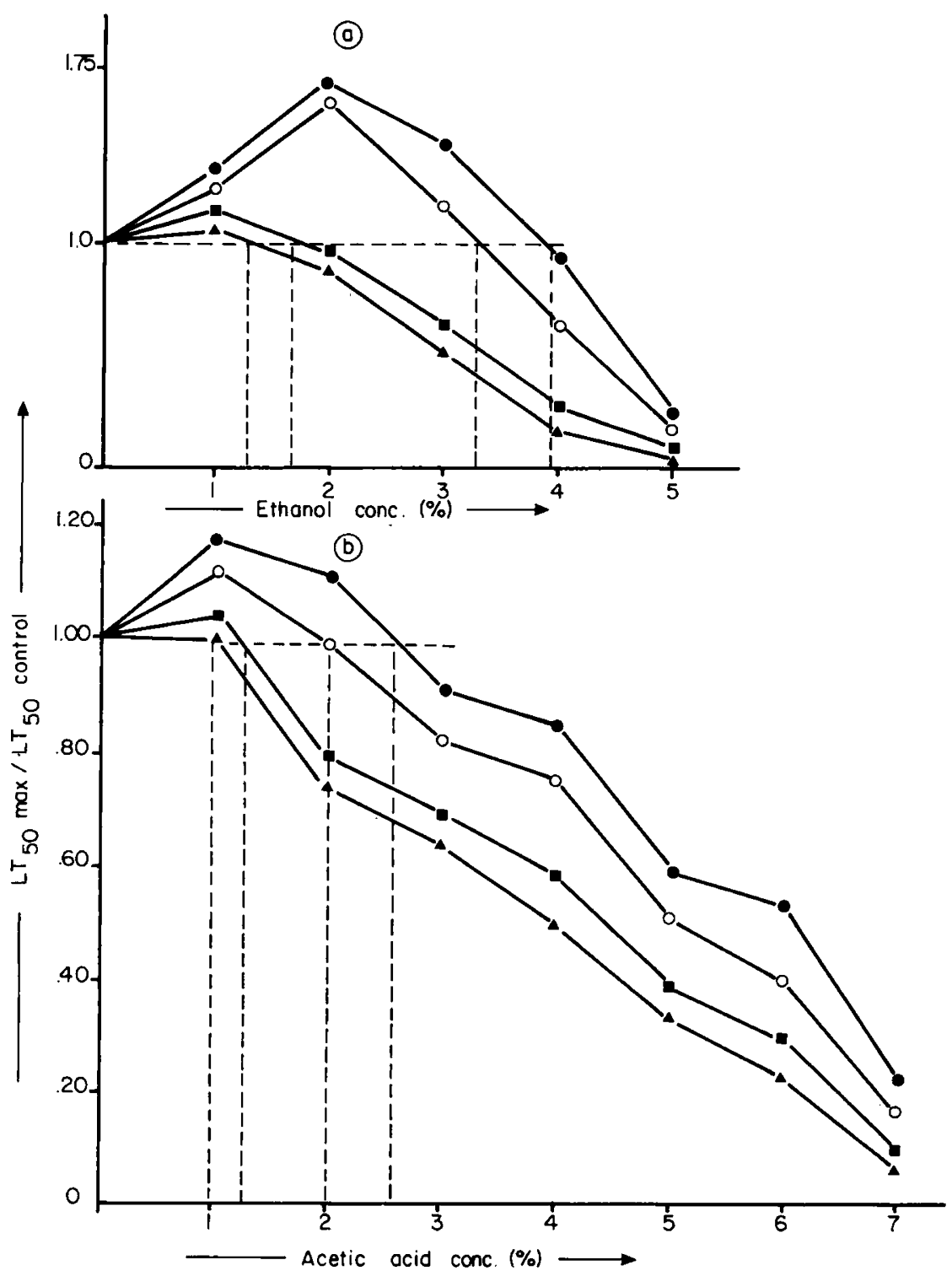

Fig 1. Relative adult longevity data $\mathrm{LT}_{50} \max / \mathrm{LT}_{50}$ control) for ethanol (a) and acetic acid (b) in $D$ immigrans populations. (Manali $\bullet-\bullet$; Rohtak o Bangalore $\mathbf{\sim} \mathbf{-}$ ). 


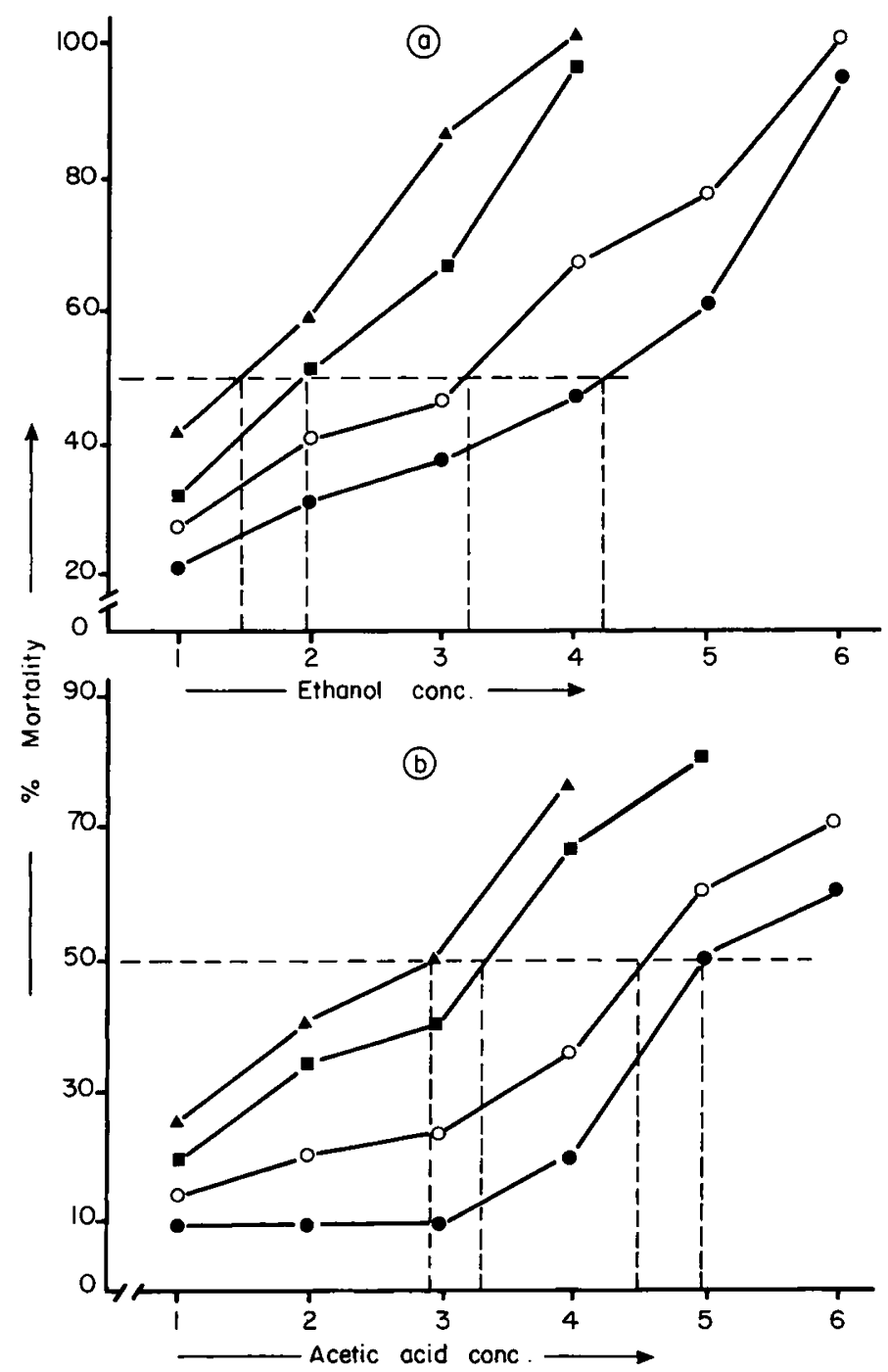

Fig 2. Percentage mortality for ethanol (a) and acetic acid (b) in $D$ immigrans populations. Symbols as in figure 1.

Interestingly, adult stages of all 4 populations of $D$ immigrans could utilise acetic acid in a parallel way to that of ethanol. The longevity data revealed parallel but lesser effect of acetic-acid utilisation. The data on acetic-acid threshold values, $\mathrm{LC}_{50}$ values, mortality and longevity responses further supported the conclusion that the acetic acid was utilised as a resource in all 4 populations of $D$ immigrans (fig $2 \mathrm{~b}$ and table I). In order to determine the extent of interpopulational divergence for acetic-acid tolerance in adult stages, an analysis of 
variance test was performed for 2 randomly selected isofemale strains of each of 4 populations of $D$ immigrans. Significant inter-populational heterogeneity was observed for different acetic-acid concentrations. The correlation was found to be significant between latitude and adult acetic-acid tolerance $(r=0.97)$. The present study provided a quantitative assessment of intra-specific patterns of resource utilisation in 4 geographical populations of $D$ immigrans which differed in adult threshold values for ethanol and acetic-acid utilisation.

\section{Microspatial differentiation}

In order to know the level of ethanol tolerance, the populations were exposed to different concentrations (1-7\%) of ethanol and acetic acid and the data on ethanol tolerance indices $\left(\mathrm{LT}_{50} \mathrm{~h}, \mathrm{LT}_{50} \mathrm{max} / \mathrm{LT}_{50}\right.$ control, adult threshold values and $\left.\mathrm{LC}_{50}\right)$ are given in table II. The maximum ethanol tolerance in fruit-stall populations of $D$ immigrans was found to be $154 \mathrm{~h}$ while sugar-mill populations revealed a significantly higher value of $212 \mathrm{~h}$ (table II). The ethanol threshold concentration was $4.1 \%$ in the case of sugar-mill populations versus $3.3 \%$ for fruit-stall populations of $D$ immigrans (fig 3 ). The survival data at $3 \%$ ethanol revealed that sugar-mill populations survived for a significantly longer duration than fruit-stall populations (fig $4 \mathrm{a}$ ). The mortality data at $4 \mathrm{~d}$ ethanol treatment also revealed a significant difference in $\mathrm{LC}_{50}$ values, ie $3.2 \%$ for fruit-stall populations and $4.5 \%$ for sugar mill populations (fig $4 \mathrm{~b}$ ). Interestingly, the adult stages of both populations (from sugar mills and fruit stalls) could utilise acetic acid in a parallel way to ethanol. The increased longevity data revealed a parallel but lesser effect of acetic-acid utilisation. The data on intraspecific variation in acetic-acid threshold values, $\mathrm{LC}_{50}$ values, mortality and longevity response revealed parallel patterns to that of ethanol utilisation (table II).

\section{DISCUSSION}

The Adh locus has been found to be monomorphic in $D$ immigrans populations. Since ethanol tolerance had been suggested to be genotype dependent, the observed intraspecific difference in ethanol tolerance in $D$ immigrans could be due to regulatory genetic mechanisms rather than to the $A d h$ locus. The northern and southern populations of $D$ immigrans from India revealed significant genetic divergence in their potential to utilise both ethanol and acetic acid. The lower threshold values of ethanol (1.3-1.7\%) and acetic-acid (1.0-1.3\%) utilisation in southern populations of $D$ immigrans seem to be correlated with the lower levels of alcohols in diverse types of the fermented sweet fruits in the tropical parts of the Indian sub-continent. $D \mathrm{im}$ migrans populations utilised ethanol and acetic-acid resources in parallel ways. The acetic-acid threshold values and $\mathrm{LC}_{50}$ values were found to be slightly lower than the ethanol utilisation indices. $D$ immigrans revealed a lack of effective allozymic polymorphism at the $A d h$ locus and lower ethanol and acetic-acid threshold indices than $D$ melanogaster.

It has been argued that neighbouring populations can undergo genetic differentiation in response to environmental heterogeneity, ie if the selection pressure is sufficiently high, the genetic differentiation of local sub-populations may take place 


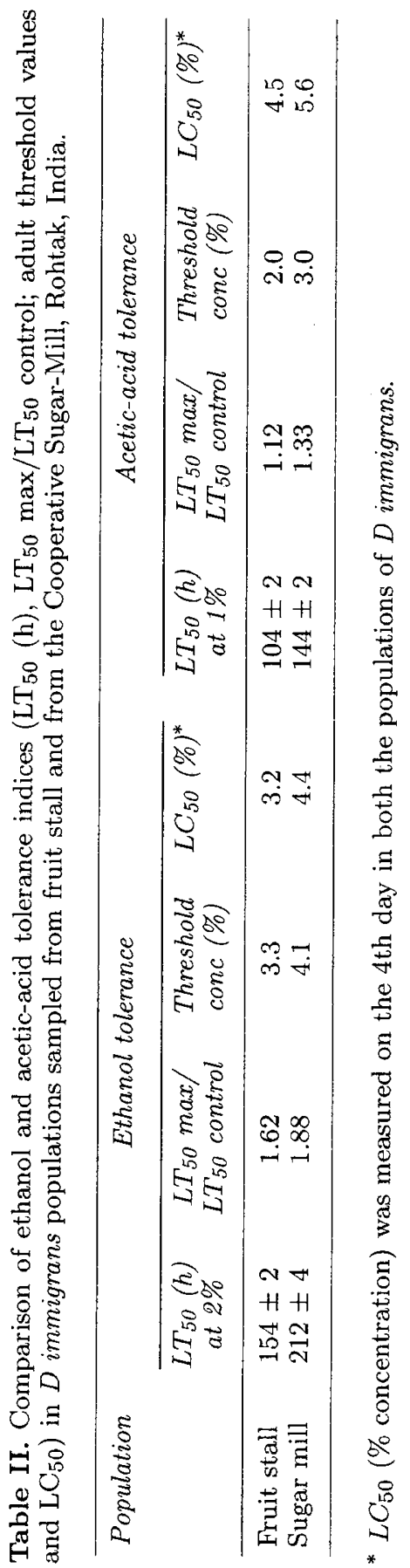




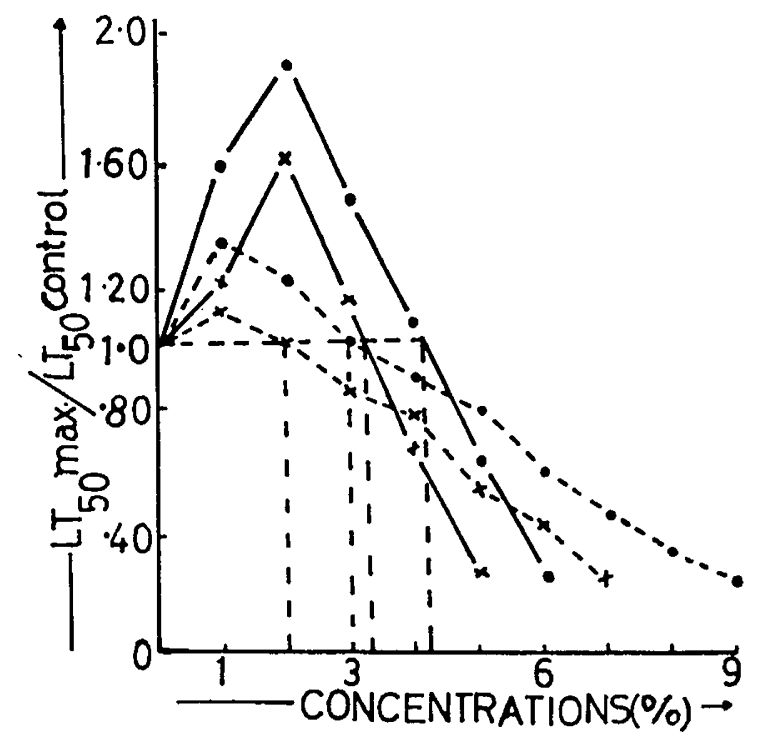

Fig 3. Ethanol (—) and acetic-acid (- . . - ) tolerance indices in the Rohtak population of $D$ immigrans collected from (a) fruit stalls $(\times-\times)$ and (b) sugar mills $(\bullet-\bullet)$ versus adult longevity (LT50 $\mathrm{max} / \mathrm{LT}_{50}$ control) for ethanol and acetic acid.

against the uniform pressure of dispersal and gene flow over short distances (Slatkin, 1987; Pecsenye, 1989; Vouidibio et al, 1989). Contrary to the earlier views of random mating populations of various drosophilids in a region, some cases of sub-divided or meta-populations under ecological or behavioural conditions have been documented (Spiess, 1989). The analysis of ethanol tolerance of $D$ immigrans flies from sugar-mill and fruit-stall areas revealed significant divergence, ie the sugar-mill population was found to be characterised as a subdivided population (metapopulation) with a distinctly higher potential of ethanol tolerance. Thus, the present results agree with the arguments of Hickey and McLean (1980) that populations located $3 \mathrm{~km}$ apart or more reveal significant differences in ethanol tolerance. The present data on ethanol tolerance lend further support to the occurrence of microspatial differentiation due to selection pressure imposed by ethanol-rich environments over a short-range distance of about $6 \mathrm{~km}$. 


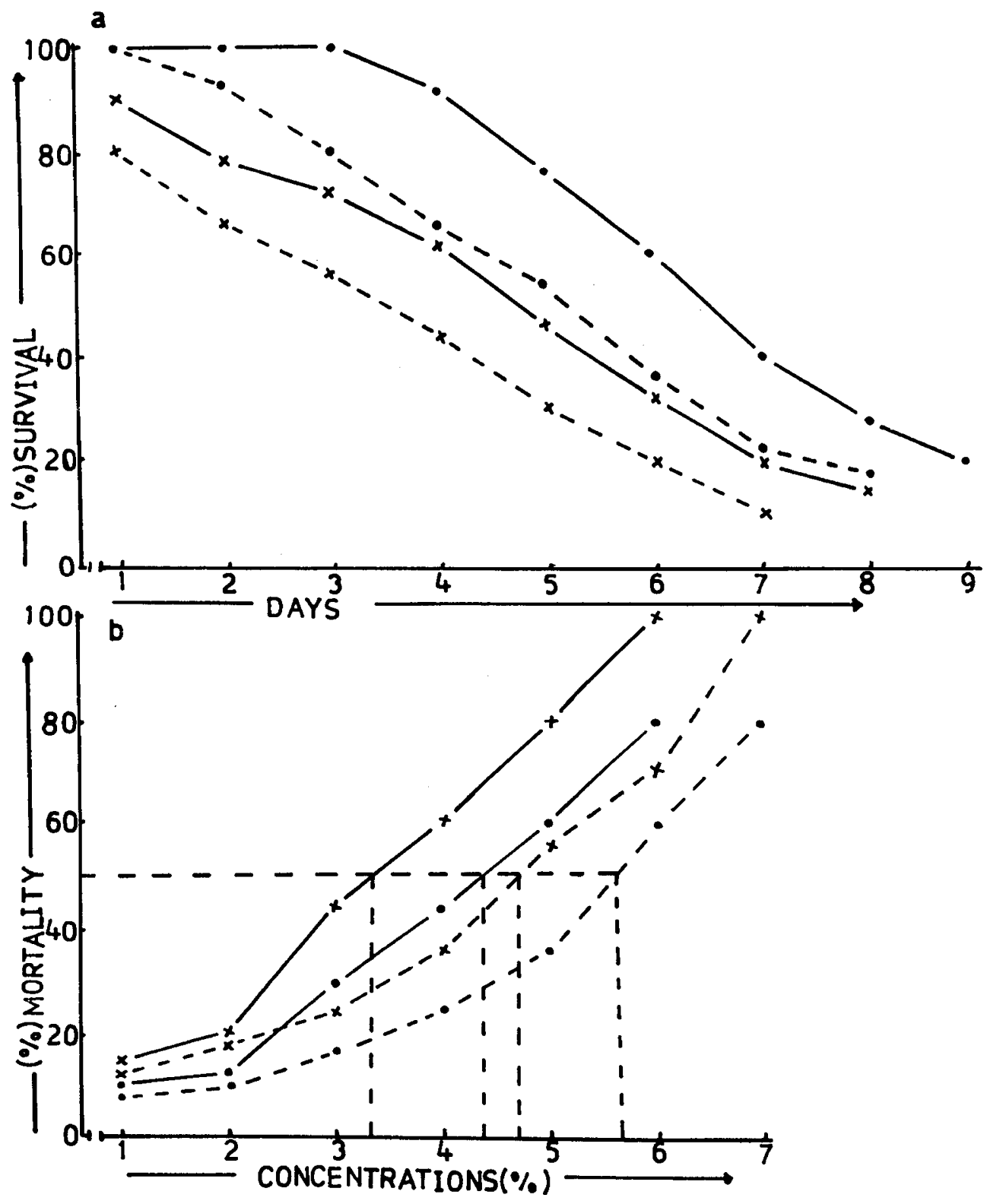

Fig 4. (a) Percent survival at 3\% ethanol (_-) and acetic acid (- - - -) in fruit stall $(\times)$ and sugar-mill $(\bullet)$ populations of $D$ immigrans. (b) Percent mortality at 3rd day of treatment for ethanol (- $\longrightarrow$ ) and acetic acid (- ..-). 


\section{ACKNOWLEDGMENTS}

The financial assistance from CSIR, New Delhi, is gratefully acknowledged. We are grateful to the reviewers for helpful comments and to $\mathrm{M}$ Weber for drawing some of the figures.

\section{REFERENCES}

Alonso-Moraga A, Munoz-Serrano A, Serradilla JM, David JR (1988) Microspatial differentiation of $D$ melanogaster populations in and around a wine cellar in southern Spain. Genet Sel Evol 20, 307-314

Atkinson W, Shorrocks B (1977) Breeding site specificity in the domestic species of Drosophila. Ecologia 29, 223-233

Carson HL (1971) The Ecology of Drosophila Breeding Sites (Lyon HL, Arboretum Lecture Number 2) Hawaii University, USA

Chakir M, Paridy O, Capy P, Pila E, David JR (1933) Adaptation to alcoholic fermentation in Drosophila: a parallel selection imposed by environmental ethanol and acetic acid. Proc Natl Acad Sci USA 90, 3621-3625

David JR, Tsacas L (1981) Cosmopolitan, sub-cosmopolitan and widespread species: different strategies within the Drosophila family. CR Soc Biogeog 57, 11-26

David JR, Van Herrewege J (1983) Adaptation to alcoholic fermentation in Drosophila species: relationship between alcohol tolerance and larval habitat. Comp Biochem Physiol 74A, 283-288

Endler JA (1977) Geographic Variation, Speciation and Clines. Princeton University Press, Princeton, NJ, USA

Endler JA (1986) Natural Selection in the Wild. Princeton University Press, Princeton, NJ, USA

Harris H, Hopkinson DA (1976) Handbook of Enzyme Electrophoresis in Human Genetics. North Holland, Amsterdam

Hickey DA, Mclean MD (1980) Selection for ethanol tolerance and Adh allozymes in natural populations of $D$ melanogaster. Genet Res 36, 11-15

Lemeunier F, David JR, Tsacas L, Ashburner M (1986) The melanogaster species group. In: The Genetics and Biology of Drosophila (M Ashburner, ML Carson, JN Thompson, eds) Acad Press, New York, London vol 3E, 147-256

McKenzie JA, Parsons PA (1972) Alcohol tolerance: an ecological parameter in the relative success of $D$ melanogaster and $D$ simulans. Ecologia 10,373-388

Parsons PA (1983) The Evolutionary Biology of Colonising Species. Cambridge Univ Press, Cambridge, UK

Parsons PA, Spence GE (1981) Ethanol utilisation: threshold differences among three Drosophila species. Amer Nat 117, 568-571

Pecsenye K (1989) A comparison of the level of enzyme polymorphism in cosmopolitan Drosophila species between populations collected in distilleries and in their surroundings in Hungary. Genet Sel Evol 21, 147-157

Slatkin M (1987) Gene flow and the geographic structure of natural populations. Science $236,787-792$

Spiess EB (1989) Genes in Populations. John Wiley and Sons, New York, USA

Starmer WT, Heed WB, Rockwood Sluss ES (1977) Extension of longevity in D mojavensis by environmental ethanol: differences between subraces. Proc Natl Acad Scie USA 74, 387-391

Vouidibio J, Capy P, Defaye D et al (1989) Short-range genetic structure of $D$ melanogaster populations in an Afrotropical urban area and its significance. Proc Natl Acad Sci USA $86,8442-8446$ 